\title{
Characteristics of rickets in a referral hospital in Khartoum-Sudan
}

\author{
Abstract \\ Rickets is a common disease among children with severe malnutrition; it may be \\ associated with liver and renal failure as precipitating factors.
}

Methods and materials: this study was done at JafarIbn Auf pediatric hospital, Sudan. Fifty-four children with rickets were included. Clinical, radiological, laboratory, as well as socioeconomic status, were assessed.

Results: The mean age of the children with rickets was $(22.3 \pm 15.1$ months $)$, $38(70.4 \%)$ of the children had low sunlight exposure, $45(83.3 \%)$ from low-income families, 50(92.2\%) were under weight, $25.9 \%$ were not breastfed, $41(75.9 \%)$ had ricketic rosary and $38(70.4 \%)$ had hand swelling. Out of all study population; $51(94.4 \%)$ of them showed hypocalcemia associated with hypophosphatemia and $50(92.6 \%)$ showed increased alkaline phosphatase levels. As risk factors; $8(14.8 \%)$ of the study population had liver failure, while $6(11.1 \%)$ had renal failure

Conclusion: Rickets in JafarIbn Auf pediatric hospital is associated with poverty and malnutrition as well as low sunlight exposure. Liver failure and renal failure may be important precipitating factors for rickets in Sudanese children.

Keywords: rickets, sunlight exposure, socioeconomic factors, liver failure, renal failure
Volume 8 Issue 5 - 2018

\author{
Mohammed Abbas, ${ }^{1,3}$ Eltayeb Tayrab, ${ }^{2,5}$ \\ Jowayria E Tayrab, ${ }^{6}$ Karimeldin Mohamed Ali \\ Salih ${ }^{1,4}$ \\ 'Department of pediatrics, college of Medicine, University of \\ Bisha, Saudi Arabia \\ 2Department of chemical pathology, Faculty of Medical \\ Laboratory Sciences, National Ribat University, Sudan \\ ${ }^{3}$ Department of pediatrics, Faculty of Medicine, Kassala \\ University, Sudan \\ ${ }^{4}$ Department of pediatrics, faculty of medicine, University of \\ Bahri, Sudan \\ ${ }^{5}$ Department of basic medical sciences, Faculty of Applied \\ Medical Sciences, University of Bisha, Saudi Arabia \\ ${ }^{6}$ Department of pediatrics, Sudan Medical Specialization Board, \\ Khartoum, Sudan
}

Correspondence: Eltayeb Mohamed Ahmed Tayrab, Associate professor of chemical pathology, Faculty of Medical Laboratory Sciences, National Ribat University, Khartoum, Sudan, P.O. Box 55, Fax 83-263590, Tel, 00249912278825 , Email eltayebtiyrab@gmail.com

Received: April 12, 2018 | Published: October 10, 2018
Abbreviations: $\mathrm{CBC}$, complete blood count; RFT, renal function; LFT, liver function

\section{Introduction}

Rickets is a disease associated with failure of mineralization of growing bones in children. ${ }^{1,2}$ Rickets may be associated with growth retardation, muscle weakness, hypocalcaemia and alopecia totalis ${ }^{3}$. Rickets results from defective metabolism of calcium, phosphorus and/or vitamin D. ${ }^{4,5,6}$ Calcium and vitamin D are important nutrients for skeletal growth and bone health. ${ }^{7}$ Rickets can be caused by nutritional deficiencies or genetic disorders. ${ }^{4}$ Nutritional rickets is a health problem in developing countries. ${ }^{8}$ The most common cause of rickets is vitamin D deficiency. ${ }^{1}$ Genetic rickets; mostly resulted from mutations in the vitamin D receptor gene. ${ }^{3,9}$ Active vitamin D has an important role in calcium regulation and bone metabolism. ${ }^{10}$ Children are particularly vulnerable to 25-hydroxyvitamin D deficiency. ${ }^{7}$ Vitamin D regulates skeletal homeostasis both indirectly and directly. ${ }^{11}$ Nutritional type rickets is a child health problem in developing countries. ${ }^{5}$ Rickets is common among children with severe acute malnutrition and it is associated with increased risks of severe pneumonia and death. ${ }^{12}$ Vitamin D deficiency with or without calcium deficiency may lead to nutritional rickets. ${ }^{7}$ Vitamin D; can be synthesized in the skin or absorbed from the diet. ${ }^{11}$ Renal disorders also effect on mineralization and may be associated with rickets. ${ }^{1}$ Generally, clinical presentation of the rickets is heterogeneous and includes bone pain and deformities, muscle weakness, short stature and profound sweating., ${ }^{4,2}$ Rickets increases children susceptibility to infectious diseases. ${ }^{11}$ There is an association between rickets and some infectious diseases like hematogenous osteomyelitis in children. ${ }^{13}$ In the differential diagnosis of different forms of rickets; the detailed family history, physical examination, biochemical assessment and X-ray imaging are required..$^{11,2}$ This study aimed to find the characteristics of rickets at JafarIbn Auf pediatric hospital in Sudan.

\section{Methodology}

This is a prospective, cross-sectional, hospital-based study, conducted at Jafarlbn Auf pediatric hospital. It is one of the first dedicated children's hospitals in Africa. It is the main referral children hospital in Khartoum. The hospital receives referral cases from all over the Sudan. The emergency room receives 250-300 cases per day. The samples were collected twice weekly. Any child suspected to have rickets(who present with delayed walking, bowing of the legs, any bone deformities and muscle weakness) or/with the clinical sign such as large head with delayed closure of the anterior fontanel, rachitic rosary and wide wrist was further investigated to detect the precipitating factors (socio-economic, renal, liver and/ or others). Fifty-four children with rickets were included. All children included in the study were seen by the registrar. Structured history checklist was used for checking (the presenting complains, past history, nutritional \& socioeconomic status). A full clinical examination was also done through checklist for any case with suspicion of rickets. Further investigations included were (complete blood count (CBC), renal function (RFT), liver function (LFT), X-Ray, serum calcium, serum phosphorus and serum alkaline phosphatase). The pediatrician reconfirmed the cases. All children enrolled in the study were Sudanese; aged less than 15 years. All cases referred or visited the 
emergency unit were included. Known cases of renal failure, liver failure, non-Sudanese or aged more than 15 years were excluded. The study was done in the period from June 2009-June 2011. WHO Child Growth Standards (2006), were used for evaluating the weight of the children under the study. ${ }^{14}$

\section{Ethical consideration}

Permission from hospital ethical and research committee was received. The informed written consents were taken from the fathers or the mothers of the children after they agreed to participate in this study.

\section{Statistical analysis}

The data were analyzed using SPSS version 20 software. Frequency, percentage, mean and standard deviation for the findings were estimated.

\section{Results}

The study revealed that; $29(53.3 \%)$ of the children with rickets were males, while $24(44.4 \%)$ were females. The (mean \pm Std) of the age of the children with rickets was $(22.3 \pm 15.1$ months); with the range (8-59 months) or under 5 years. Concerning socioeconomic status; $45(83.3 \%)$ of the children with rickets came from lowincome families, while $7(13.0 \%)$ of them came from moderateincome families. The study showed good educational background for the parents $(>96 \%)$. Children with rickets experienced breastfeeding were $38(70.4 \%)$, while those who do not breastfed were $14(25.9 \%)$. Children who were enough exposed to sunlight per day were $14(25.9 \%)$, while those without enough exposure to sunlight were $38(70.4 \%)$. Underweight children were 50(92.2\%), and those with the normal weight according to WHO standards were $2(3.7 \%)$, (Table 1). The laboratory findings showed that; 51(94.4\%) of the children under study had both hypocalcaemia and hypophosphatemia, while alkaline phosphatase enzyme was increased in 50(92.6\%) of the subjects, (Table 2). The precipitating factors were as follow; $8(14.8 \%)$ had liver failure, $6(11.1 \%)$ had renal failure (Table $3)$. Some data were missed during the study and appeared in the descriptive (Table $1 \&$ Table 3).

Table I Distribution of the study population according to the precipitating factors $(\mathrm{N}=54)$

\begin{tabular}{lll}
\hline General characteristics & Frequency & Percentage (\%) \\
\hline Gender of the children & & \\
Males & 29 & 53.3 \\
Females & 24 & 44.4 \\
missed data & $\mathrm{I}$ & 1.9 \\
Socioeconomic status of the family & \\
Low income & 45 & 83.3 \\
Moderate income & 7 & 13 \\
Missed data & 2 & 3.7 \\
Educational level (Father) & & \\
Primary & 9 & 16.7 \\
\hline
\end{tabular}

Table continued...

\begin{tabular}{|c|c|c|}
\hline General characteristics & Frequency & Percentage (\%) \\
\hline Secondary & 13 & 24.1 \\
\hline University & 30 & 55.6 \\
\hline Missed data & 2 & 3.7 \\
\hline \multicolumn{3}{|c|}{ Educational level (Mother) } \\
\hline Primary & 13 & 24.1 \\
\hline Secondary & 22 & 40.7 \\
\hline University & 17 & 31.5 \\
\hline Missed data & 2 & 3.7 \\
\hline \multicolumn{3}{|l|}{ Breastfeeding } \\
\hline Yes & 38 & 70.4 \\
\hline No & 14 & 25.9 \\
\hline Missed data & 2 & 3.7 \\
\hline \multicolumn{3}{|l|}{ Child sun light exposure } \\
\hline Yes & 14 & 25.9 \\
\hline No & 38 & 70.4 \\
\hline Missed data & 2 & 3.7 \\
\hline \multicolumn{3}{|l|}{ Child weight } \\
\hline Under weight & 50 & 92.6 \\
\hline Normal weight & 2 & 3.7 \\
\hline Missed data & 2 & 3.7 \\
\hline \multicolumn{3}{|l|}{ Others: } \\
\hline Liver failure & 8 & 14.8 \\
\hline Renal failure & 6 & 11.1 \\
\hline No complications & 40 & 74.1 \\
\hline
\end{tabular}

Table 2 Distribution of the study population according to the laboratory findings $(N=54)$

\begin{tabular}{lcl}
\hline Laboratory findings & Frequency & Percentage (\%) \\
\hline Serum calcium & & \\
Hypocalcemia & $5 \mathrm{I}$ & 94.4 \\
Normal & $\mathrm{I}$ & 1.9 \\
Missed data & 2 & 3.7 \\
Serum phosphates & & \\
Hypophosphatemia & $5 \mathrm{I}$ & 94.4 \\
Normal & $\mathrm{I}$ & 1.9 \\
Missed data & 2 & 3.7 \\
Serum alkaline phosphatase & \\
Increased & 50 & 92.6 \\
Normal & $\mathrm{I}$ & 1.9 \\
Missed data & 3 & 5.6 \\
\hline
\end{tabular}


Table 3 Distribution of the study population according to the clinical signs $(\mathrm{N}=54)$

\begin{tabular}{lllll}
\hline $\begin{array}{l}\text { Clinical } \\
\text { symptoms }\end{array}$ & Frequency & $\begin{array}{l}\text { Gender } \\
\text { distribution }\end{array}$ & Percentage (\%) \\
\hline $\begin{array}{l}\text { Ricketic rosary } \\
\text { Yes }\end{array}$ & 41 & $\begin{array}{l}\text { males } \\
\text { females }\end{array}$ & 19 & 75.9 \\
No & 12 & & & 22.2 \\
missed data & 1 & & 1.9 \\
Hands swelling & & males & 20 & 70.4 \\
Yes & 38 & females & 18 & \\
& & & & 27.8 \\
No & 15 & & & 1.9 \\
Missed data & 1 & & & \\
\hline
\end{tabular}

\section{Discussion}

Rickets is a complex disease; it has many sequences on child health and life expectancy. In this study rickets is associated with the socioeconomic status of the family; that $83.3 \%$ of children with rickets brought to the clinic from low-income families, knowing that $92.6 \%$ were underweight and $25.9 \%$ were not breastfed, (Table 1). These factors may be accounted as nutritional related rickets, which is very common in developing countries, as reported in Kenya by Karuri et al., ${ }^{8}$ In normal conditions; if the child is underweight and/or not breastfed, the parents can find to him a substitution milk or supplementary food to fill the gap, but in low-income families as in the most cases of this study, they can't, because the child may have other siblings which worsen the status, leading to malnutrition and its complications. So nutritional rickets can be suspected. It is strange that some children in Sudan as one of the tropical countries do not expose to sunlight for minimum 30 minutes per day. In this study, $70.4 \%$ of children with rickets do not have enough exposure to sunlight. It is known that rickets may results from defective metabolism of calcium, phosphorus and/or vitamin D. It's also known that vitamin $\mathrm{D}$ in children, can be easily synthesized in the skin when the child is exposed to sunlight especially in the early morning where ultraviolet light is concentrated as reported recently by Goltzman. ${ }^{11}$ Vitamin $\mathrm{D}$ undergoes multi-steps enzymatic conversion to form the active 1,25-dihydroxy vitamin D in the kidney which is the most important Vitamin D as stated by Goltzman. ${ }^{11}$ Contrary to these facts; some researchers believe that sunlight may cause melanomas especially in cold countries. Regarding the risk factors of rickets; this study assessed many risk factors including educational background, the income of the family, sun exposure, nutritional status, besides these factors, this research found that $14.8 \%$ of children had almost liver failure, while $11.1 \%$ had renal failure. The late two diseases are life treating to the children in the presence of rickets. Even the researcher cannot exclude the other factors that may contribute to these diseases. In this study, $94.4 \%$ of all cases showed hypocalcemia associated with hypophosphatemia. The factors that give both hypocalcemia and hypophosphatemia are vitamin D deficiency and increased renal loss as reported by Nessar \& Behzad. ${ }^{15}$ Hypocalcemia may be arising from a decreased absorption of calcium from the gastrointestinal tract, or a result of the decreased loss from bones or increased calcium excretion by the kidney. However; hypophosphatemia may be caused by increased renal loss, decreased intake, cellular uptake, or due to genetic mutation in the gene FGF23 leading to renal phosphate wasting and hence hypophosphatemia as written by Goldstein \& Carpenter. ${ }^{16}$ In this research, alkaline phosphatase enzyme increased in $92.6 \%$ of cases. Optimum level of this enzyme is crucial for the normal growth of bone and teeth. This enzyme is the one of corner stones in the metabolism of calcium and phosphorous as reported by Nessar and colleagues. ${ }^{15}$ On the other hand, $92.2 \%$ of the children under the study were under weight, while $75.9 \%$ of them had ricketic rosary and $70.4 \%$ had hands swelling. Rickets also reduces the body immune and the child become more susceptible to infectious disease especially osteomyelitis as stated by John and colleagues..$^{13}$

\section{Conclusion}

Rickets in Jafarlbn Auf pediatric hospital is associated with poverty, malnutrition and low sunlight exposure. Hypocalcemia, hypophosphatemia as well as increased alkaline phosphatase are predominant. Liver and renal failure is suspicious risk factors for the rickets. More research is required using big samples size to realize the facts.

\section{Acknowledgements}

None.

\section{Conflict of interest}

The authors declare that no conflict of interest.

\section{References}

1. Allgrove J, Shaw NJ. A practical approach to vitamin D deficiency and Rickets. Endocr Dev. 2015; 28:119-33.

2. Kutilek S, Skalova S. Erroneous diagnosis of rickets. Turk Pediatri Ars. 2017;552(3):178-179.

3. Ghazi AA1, Zadeh-Vakili A2, Zarif Yeganeh M, et al. Hereditary vitamin D resistant rickets: Clinical, laboratory, and genetic characteristics of 2 Iranian siblings. Int J Endocrinol Metab. 2017;15(3): e12384.

4. Carpenter TO, Shaw NJ, Portale AA, et al. Rickets. Nat Rev Dis Primers. 2017;3:17101.

5. Acar S, Demir K, Shi Y. Genetic causes of rickets. J Clin Res Pediatr Endocrinol. 2017;9(Suppl 2):88-105.

6. Mankin HJ. Rickets, osteomalacia, and renal osteodystrophy. An update. Orthop Clin North Am. 1990;21(1):81-96.

7. Fiscaletti M, Stewart P, Munnns CF. The importance of vitamin D in maternal and child health: a global perspective. Public Health Rev. 2017;38:19.

8. Karuri SW, Murithi MK, Irimu G, et al. Using data from a multi-hospital clinical network to explore prevalence of pediatric rickets in Kenya. Wellcome Open Res. 2017;2:64.

9. Michalus I, Rusinka A. Rare, genetically conditioned forms of rickets - differential diagnosis and advances in diagnostics and treatment. Clin Genet. 2018; 94(1):103-114.

10. Nakanishi S, Fukagawa M. Role of vitamin D in the pathogenesis of renal osteodystrophy. Clin Calcium. 2004;14(9):15-20.

11. Goltzman D. Functions of vitamin D in bone. Histochem Cell Biol. 2018;149(4):305-312. 
12. Ngari MM, Thitiri J, Mwalekwa L, et al. The impact of rickets on growth and morbidity during recovery among children with complicated severe acute malnutrition in Kenya: A cohort study. Matern Child Nutr. 2018; 14(2):e12569.

13. John M, Al-Jadiri A, Co C, et al. Acute hematogenous osteomyelitis in a five-month-old male with rickets. Case Reports in Pediatrics. 2017;2017.

14. WHO. Multi centre growth reference study group. WHO child growth standards: Length/height-for-age, weight-for-age, weight-forlength, weight-for-height and body mass index-for-age: Methods and development. Geneva: World Health Organization, 2006.
15. Nessar A, Farhad B. Disorders of calcium, phosphates, and magnesium homeostasis. (clinical biochemistry). Oxford university press, New York, 2011 .

16. Goldsweig BK, Carpenter TO. Hypophosphatemic rickets: lessons from disrupted FGF23 control of phosphorus homeostasis. Curr Osteoporos Rep. 2015;13(2):88-97. 